\title{
Alternative Evaluation of an ELISPOT Assay Using Cytokine Activity as a Novel Parameter
}

\author{
CHIE MAEDA ${ }^{1}$, AKIRA IIZUKA ${ }^{1}$, HARUO MIYATA ${ }^{1}$, RYOTA KONDOU $^{1}$, TADASHI ASHIZAWA ${ }^{1}$, \\ AKARI KANEMATSU ${ }^{1}$, KYOKO WATANABE $^{1}$, SHOICHI DEGUCHI ${ }^{2}$, KOICHI MITSUYA $^{2}$, \\ NAKAMASA HAYASHI ${ }^{2}$, YOSHIAKI ABE ${ }^{3}$, KEN YAMAGUCHI ${ }^{4}$ and YASUTO AKIYAMA ${ }^{1}$ \\ ${ }^{1}$ Immunotherapy Division, Shizuoka Cancer Center Research Institute, ${ }^{2}$ Division of Neurosurgery, \\ ${ }^{3}$ Division of Blood Transfusion, ${ }^{4}$ Office of the President, Shizuoka Cancer Center Hospital, Shizuoka, Japan
}

\begin{abstract}
Background/Aim: The enzyme-linked immunospot (ELISPOT) assay is a well-established method used to evaluate the strength of $T$ cell-mediated immune activity, and accepted as a standard functional immunological assay. Cytokine activity is a novel parameter reflecting spot size and intensity, which has not been used in ELISPOT assay before. Materials and Methods: In the present study, from 113 ELISPOT assay data derived from previous clinical trials with dendritic cell vaccines, both spot number count and cytokine activity data for IFN- $\gamma$ secretion were obtained using an ELISPOT reader. Comparing the new parameter cytokine activity with the existing parameter spot number, the feasibility of cytokine activity was investigated. Results: There were no significant differences in sensitivity and specificity between spot number and cytokine activity among ELISPOT assay data from CMVpp65 and other antigen peptide-stimulated cytotoxic T lymphocytes. Conclusion: Although cytokine activity is a novel parameter unreported so far, it did not show any advantages in the evaluation $T$ cell immune responses compared to the existing spot number parameter.
\end{abstract}

The enzyme-linked immunospot assay (ELISPOT) was first reported by Czerkinsky et al., and is available worldwide as a functional immunological assay for single-cell analysis (1,

This article is freely accessible online.

Correspondence to: Yasuto Akiyama, Immunotherapy Division, Shizuoka Cancer Center Research Institute, 1007 Shimonagakubo, Nagaizumi-cho, Sunto-gun, Shizuoka 411-8777, Japan. Tel: +81 559895222 (ext. 5330), Fax: +81 559896085, e-mail: y.akiyama@scchr.jp

Key Words: ELISPOT assay, spot number, cytokine activity, ELISPOT reader, HLA.
2). Because of the easy establishment and performance of the assay system and high assay sensitivity, ELISPOT assays have been widely applied, ranging from laboratory experiments using animal models to clinical translational research, and multiple cytokine-secreting clonal $\mathrm{T}$ cells can be enumerated on a single-cell basis (3-8).

In contrast to the worldwide availability, the high grade of discrepancy and variability in ELISPOT measurement results among different laboratories has been a major challenge to medical immunologists and oncologists involved in clinical immunotherapy $(9,10)$. Generally, there are two major reasons responsible for the high grade of variability in ELISPOT results: the first is the difference in experimental protocols and instruments, and the second is the differences in data analysis methods.

To address this variability, a large-scale immune monitoring harmonization process, which was conducted by the Cancer Vaccine Consortium of the Sabin Vaccine Institute (CVC/SVI), was successfully performed through an external validation program. Janetzki et al. reported harmonization guidelines in 2008, which demonstrated a significant improvement in ELISPOT assay performance $(11,12)$.

Furthermore, there are three main parameters, spot number, spot size, and spot intensity used to analyze ELISPOT assay results. Regularly, spot number seems to be a standard parameter for evaluating the immune response (13-15); however, spot size and intensity parameters are sometimes helpful (16). Cytokine activity is a specific parameter that can be calculated from spot size and intensity values using the formula shown in Figure 1 and is available on an Autoimmun Diagnostika (AID) ELISPOT reader (17). However, cytokine activity has not been reported in the past literature.

In the current study, we focused on the cytokine activity parameter, comparing this parameter with the spot number counted on an AID system; eventually, the feasibility of the cytokine activity parameter was investigated. 


\section{Cytokine Activity}

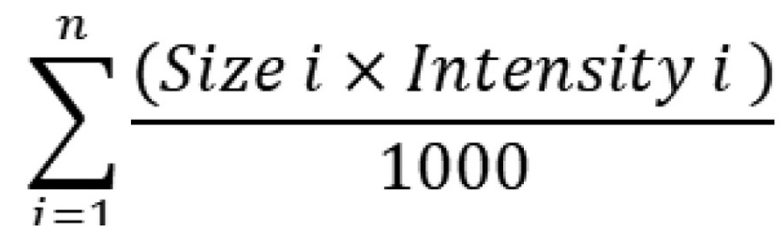

Figure 1. The formula for calculating cytokine activity. Cytokine activity is a specific parameter that can be calculated from spot size and intensity values.

\section{Materials and Methods}

Cancer patients enrolled in dendritic cell vaccine clinical trials. Twenty cancer patients (6 melanoma patients and 14 glioblastoma patients) were enrolled in dendritic cell (DC)-vaccine-based clinical trials and evaluated with ELISPOT assays (Table I). The HLA-A2and A24-positive case numbers were 4 and 16, respectively. Peripheral blood mononuclear cells (PBMCs) from these patients were utilized for cytotoxic T lymphocyte (CTL) production assays with stimulation by HLA-A2- or HLA-A24-restricted CMVpp65 epitope or other peptide and eventually IFN- $\gamma$-associated spots were analyzed on an ELISPOT reader. Seventy-nine and 34 ELISPOT assays from CMVpp65- and other peptide-stimulated CTLs, respectively were given assay ID numbers and all results were investigated in the present study. In another experiment, the amount of IFN- $\gamma$ secreted by cultured CTLs stimulated with CMVpp65 peptides was measured using ELISA.

ELISPOT assay. The ELISPOT assay was performed using PBMCs drawn prior to vaccination and after $4 \mathrm{DC}$ injections, and the human IFN- $\gamma$ ELISpot BASIC kit (3420-2A, MABTECH AB, Nacka, Sweden) was used as described previously $(18,19)$. Briefly, on day 1, HLA-A2- or HLA-A24-restricted CMVpp65 or other peptides were added to PBMCs in a 24-well culture plate and incubated in the presence of IL-2 and IL-7 for one week. On day 7, nonadherent cells were stimulated with adherent cells treated with CMVpp65 or other peptides again. On day 14, the responder cells were stimulated overnight with each peptide in a polyvinylidene fluoride (PVDF) plate coated with an anti-IFN- $\gamma$ antibody (MultiScreen, MAIPS4510, Merck Millipore, Burlington, MA, USA). Finally, the positive spots stained with the anti-IFN- $\gamma$ antibody were measured using an AID ELISPOT reader (Autoimmun Diagnostika GmbH, Strassberg, Germany).

Specifically, according to the manufacturer's instructions, appropriate measurement conditions were set up as follows: spot count setting with a minimum intensity of 20 , minimum gradient of 1.0 and minimum size of 30 . The formula for calculating the cytokine activity parameter using spot size and intensity values is shown in Figure 1.

CTL induction cultures. PBMCs from melanoma patients and glioma patients were used for in vitro CTL induction (Clinical research using PBMCs and tumor tissues from cancer patients was approved by the Institutional Review Board of Shizuoka Cancer Center, Shizuoka, Japan). All patients gave written informed
Table I. Characteristics of patients enrolled in ELISPOT assays in terms of HLA typing.

\begin{tabular}{lcc}
\hline HLA type & Case No. & Assay No. \\
\hline A2 & 4 (GB 4) & 25 (GB 25) \\
A24 & 16 (GB10, MEL6) & 88 (GB 56, MEL 32) \\
\hline Total & 20 & $113 *$ \\
\hline
\end{tabular}

GB: Glioblastoma patients; MEL: melanoma patients. *Among 113 ELISPOT assays, 79 assays were from CMVpp65 peptide-stimulated CTL cultures and the remaining 34 assays were from other antigen peptide-stimulated cultures.

consent. The method of CTL induction cultures has been previously described (20).

IFN- $\gamma$ production assay. T2 cells or TISI cells (20) were incubated overnight with the HLA-A2- or HLA-A24-restricted CMVpp65 peptide at $20 \mu \mathrm{g} / \mathrm{ml}$, suspended in PBS (+) containing $1 \%$ human serum albumin (HSA), and prepared as target cells. Cultured CTLs $\left(1 \times 10^{5}\right)$ and CMVpp65 peptide-pulsed TISI cells $\left(1 \times 10^{5}\right)$ were coincubated in a 96-well round-bottomed microculture plate for $24 \mathrm{~h}$. Finally, the supernatants were collected and IFN- $\gamma$ levels were measured using Human IFN- $\gamma$ ELISA MAX ${ }^{\mathrm{TM}}$ Standard (BioLegend, San Diego, CA, USA).

Statistical analysis. To test the log-normal distribution of spot numbers and cytokine activity calculated from spot sizes and intensity values, the Kolmogorov-Smirnov fit test was performed using the freely available EZR software (21) and Microsoft Excel. The relationship between spot number and cytokine activity values of triplicate samples was analyzed using the Pearson coefficient test. The significance of differences between unstimulated and stimulated T cell responses generated with the CMVpp65 or other peptides in terms of ELISPOT number, cytokine activity or IFN- $\gamma$ production level was evaluated using a paired two-tailed Student's $t$-test. Values of $p<0.05$ were considered to be indicative of statistical significance.

\section{Results}

Spot number and cytokine activity parameters follow a lognormal distribution. The spot size and cytokine activity distributions of 43 positive ELISPOT result datasets from CMVpp65-stimulated CTLs were established. The normality of the spot number and cytokine activity distributions was tested using the Kolmogorov-Smirnov fit test. As a result, spot number and cytokine activity parameters followed a lognormal distribution (Figure 2A and B).

Relationship between any two parameters among spot number, cytokine activity and IFN- $\gamma$ production level. The relationship between any two parameters was investigated using the Pearson coefficient test. The spot number count and cytokine activity showed a very strong positive relationship ( $r=0.963$ ) (Figure 3A). Furthermore, there were 

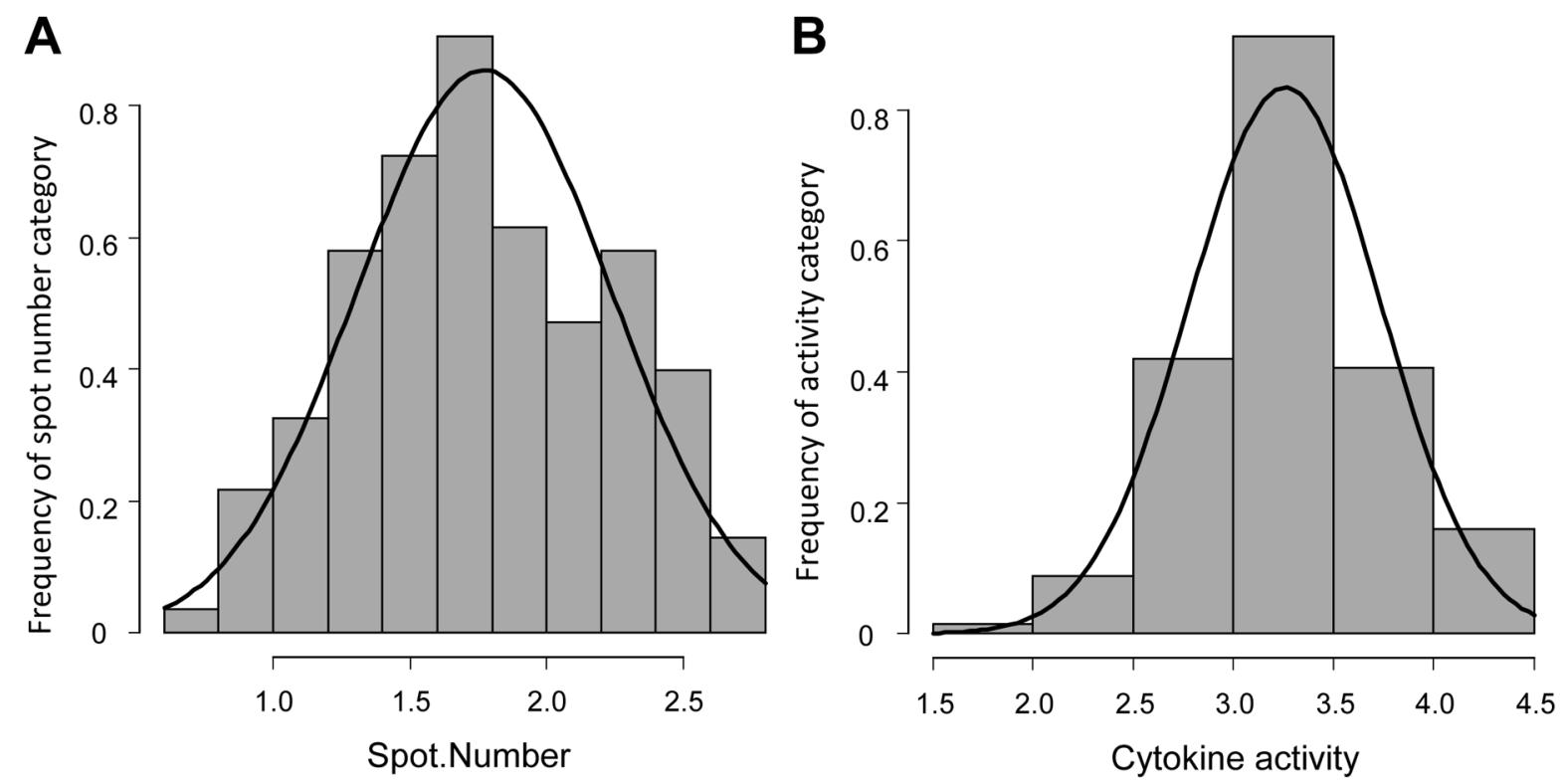

Figure 2. Spot number and cytokine activity parameters follow a log-normal distribution. The spot size and cytokine activity distributions of 43 positive ELISPOT result datasets from CMVpp65 peptide-stimulated cytotoxic T cells were established. The normality of the spot number and cytokine activity distributions was tested at a significance level of 0.05 using the Kolmogorov-Smirnov fit test, which resulted in p-values of 0.3822 and 0.7052 , respectively.

eight cases in which spot number, cytokine activity, and IFN$\gamma$ production data were obtained from ELISPOT assays and CTL cultures stimulated with CMVpp65 peptides (Table II). Comparing spot number and cytokine activity with IFN- $\gamma$ levels, it was revealed that these two parameters showed moderately positive relationships with IFN- $\gamma$ production levels (Figure 3B).

Comparison between spot number and cytokine activity in terms of $T$ cell responses to CMVpp65 or other peptides in an ELISPOT assay. Seventy-nine assays consisted of positive responses (44 assays) and negative responses (35 assays) to a cytomegalovirus (CMV) pp65 antigen peptide in terms of spot number count. Furthermore, 4 of 35 assays with a negative response based on spot number counting were found to be positive for cytokine activity. Interestingly, the cytokine activity showed similar (5 spot count-positive assays out of 36 cytokine activity-negative assays) results as the spot number data (Figure 4A). As to other peptideassociated ELISPOT responses, positive rates were not so different between spot number and cytokine activity. Similarly, sensitivity and specificity between spot number and cytokine did not show significant difference in various peptide-associated ELISPOT assays (Figure 4B).

Representative images of both spot number and cytokine activity positive cases, spot number-positive only cases, and cytokine activity-positive only cases are shown in Figure 5.

\section{Discussion}

The ELISPOT assay is widely available in settings ranging from laboratory experiments to immunotherapy-based clinical trials and is commonly applied to the efficient evaluation of immune responses as an immunological monitoring method. Despite worldwide availability, a high grade of variability in ELISPOT measurement results, such as spot number variation among different laboratories, has been a major problem in clinical settings $(9,10)$. Recently, as a harmonization program to solve such variability, guidelines for the automated evaluation of ELISPOT assays were established by Janetzki et al. (22-24) in terms of the revision of the protocol and analysis method, resulting in a further reduction in variability and an increase in the reliability of the ELISPOT assay. Additionally, there are four main providers for ELISPOT reader systems: AVEIS, AID (17), Bio-Sys, and Cellular Technology. Cytokine activity is an available measurement parameter on the AID ELISPOT reader, which has not yet been reported in the literature, and is very specific in terms of reflecting features such as spot size and intensity other than spot number.

Additionally, there are two advanced technologies to improve the efficiency of the ELISPOT assay. The first is multicolor-based ELISPOT technology development; an antigen-specific B cell detection system using an antigentagged fluorospot assay (25) and a human four-color IFN- $\gamma$, 

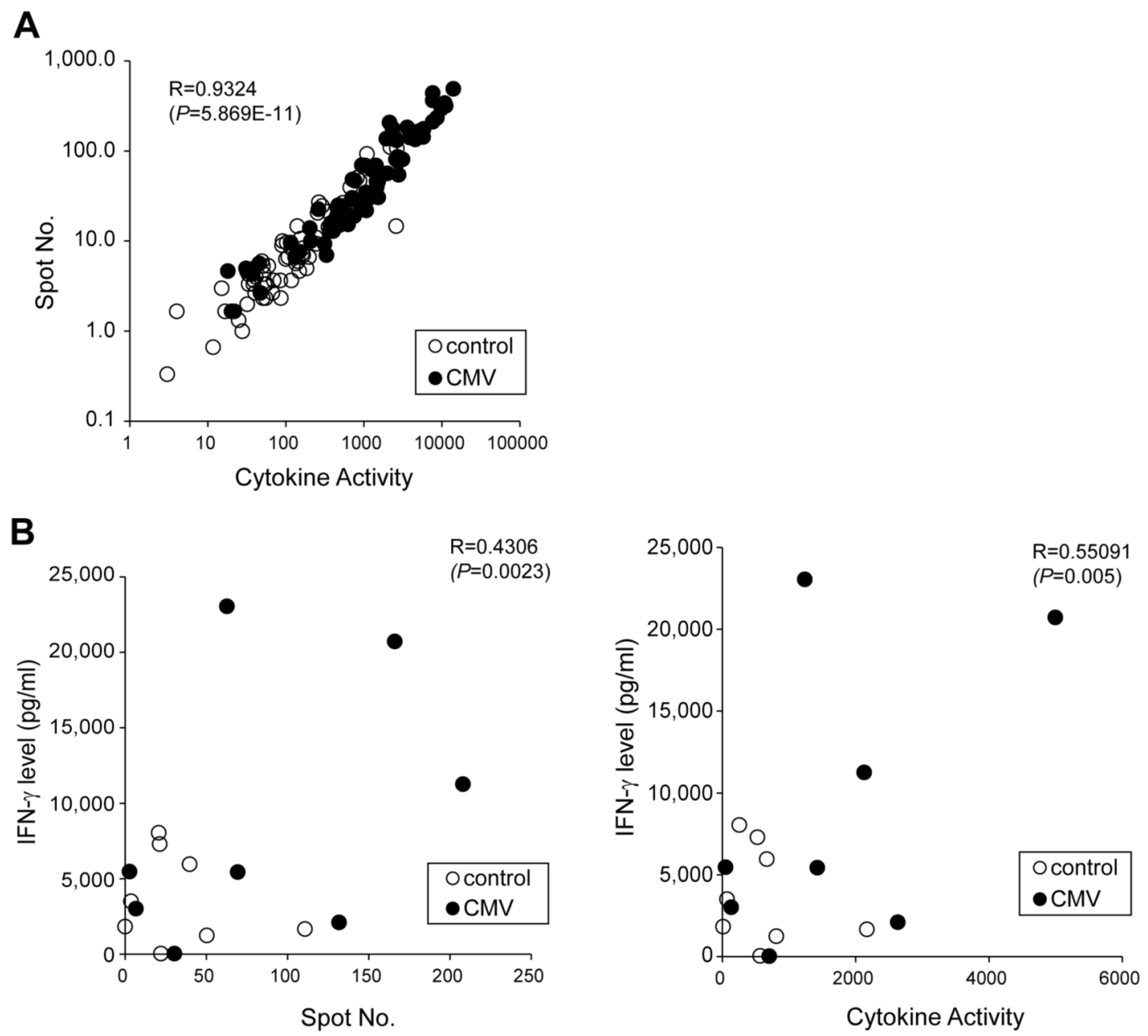

Figure 3. The relationship between any two parameters among spot number, cytokine activity, and IFN- $\gamma$ production levels from CMVpp65 peptidestimulated ELISPOT assays. The relationship between any two parameters was investigated using the Pearson coefficient test. (A) The correlation between spot number and cytokine activity using 79 ELISPOT assay stimulated with CMVpp65 peptide. (B) The correlations between spot number or cytokine activity and IFN- $\gamma$ levels secreted from cytotoxic T lymphocyte (CTL) cultures using 8 cases in which data for all 3 parameters were obtained. Control: CTL cultures without a CMV peptide; CMV: CTL cultures stimulated with a CMV peptide; R: coefficient value of the Pearson test. $p<0.05$ was considered statistically significant.

Table II. Comparison of three parameters (spot number, activity and IFN- $\gamma$ level) in 8 assays.

\begin{tabular}{|c|c|c|c|c|c|c|c|c|c|}
\hline \multirow[t]{2}{*}{ ID } & \multicolumn{3}{|c|}{ Spot No. } & \multicolumn{3}{|c|}{ Cytokine activity } & \multicolumn{3}{|c|}{ IFN- $\gamma$ level $(\mathrm{pg} / \mathrm{ml})$} \\
\hline & Control & $\mathrm{CMV}$ & $p$-Value & Control & CMV & $p$-Value & Control & $\mathrm{CMV}$ & $p$-Value \\
\hline 29 & $22.0 \pm 6.2$ & $30.3 \pm 14.1$ & 0.5032 & $568 \pm 105$ & $704 \pm 344$ & 0.6381 & $45.6 \pm 15.0$ & $32.9 \pm 11.8$ & 0.4007 \\
\hline 30 & $50.3 \pm 7.4$ & $69.3 \pm 21.0$ & 0.3304 & $810 \pm 151$ & $1,425 \pm 392$ & 0.1448 & $1,247 \pm 181$ & $5,436 \pm 113$ & $4.45 \mathrm{E}-06 * *$ \\
\hline 33 & $3.7 \pm 1.0$ & $6.7 \pm 1.9$ & 0.1447 & $69.7 \pm 29.5$ & $131 \pm 33.0$ & 0.1277 & $3,508 \pm 398$ & $3,022 \pm 79.5$ & 0.1651 \\
\hline 34 & 0 & $2.7 \pm 3.1$ & 0.3468 & $12.7 \pm 17.9$ & $47.0 \pm 55.5$ & 0.4797 & $1,826 \pm 191$ & $5,468 \pm 185$ & $4.23 \mathrm{E}-06^{* *}$ \\
\hline 36 & $111 \pm 39.4$ & $132 \pm 40.8$ & 0.6282 & $2,168 \pm 939$ & $2,633 \pm 953$ & 0.6487 & $1,661 \pm 91.4$ & $2,097 \pm 231$ & 0.0680 \\
\hline 40 & $21.3 \pm 1.7$ & $166 \pm 15.9$ & $0.0055^{*}$ & $526 \pm 86.6$ & $4,993 \pm 247$ & $0.0005 * *$ & $7,295 \pm 133$ & $20,721 \pm 962$ & $4.05 \mathrm{E}-05 * *$ \\
\hline 42 & $20.7 \pm 23.0$ & $208 \pm 103$ & 0.1194 & $255 \pm 333$ & $2,129 \pm 1,230$ & 0.1575 & $8,040 \pm 271$ & $11,258 \pm 171$ & $0.0001 * *$ \\
\hline 41 & $39.7 \pm 10.9$ & $62.7 \pm 11.1$ & 0.1046 & $667 \pm 162$ & $1,238 \pm 302$ & 0.0975 & $5,961 \pm 869$ & $23,043 \pm 1,213$ & $0.0001 * *$ \\
\hline
\end{tabular}

There were eight cases in which spot number, cytokine activity and IFN- $\gamma$ production data were obtained from CTL cultures with CMVpp65 peptides. Each value shows the mean \pm SD of the triplicate samples. The statistical significance between control and CMV peptide-stimulated group in each parameter was investigated using paired tow-tailed Student's $t$-test. Values of $p<0.05$ were considered to be significant. $* p<0.01$, ** $p<0.001$. 
A

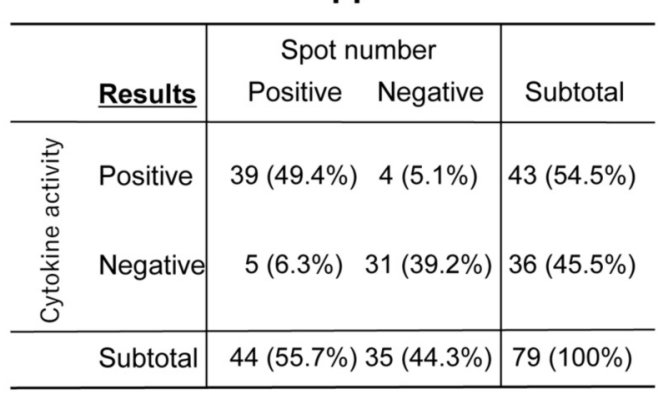

WT-1

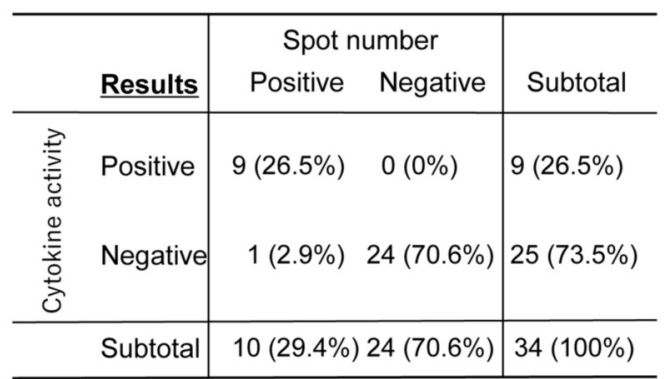

MAGEA3

\begin{tabular}{|c|c|c|c|c|}
\hline \multirow{2}{*}{\multicolumn{2}{|c|}{ esults }} & \multicolumn{2}{|c|}{ Spot number } & \multirow[b]{2}{*}{ Subtotal } \\
\hline & & Positive & Negative & \\
\hline \multirow{3}{*}{ 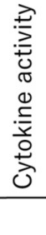 } & Positive & $10(29.4 \%)$ & $2(5.9 \%)$ & $12(35.3 \%)$ \\
\hline & Negative & $4(11.8 \%)$ & $18(52.9 \%)$ & $22(64.7 \%)$ \\
\hline & Subtotal & $14(41.2 \%)$ & $20(58.8 \%)$ & $34(100 \%)$ \\
\hline
\end{tabular}

B

\begin{tabular}{c|cccccc}
\hline & \multicolumn{2}{|c}{ CMVpp65 } & \multicolumn{2}{c}{ MAGEA3 } & \multicolumn{2}{c}{ WT-1 } \\
Results & SE & SP & SE & SP & SE & SP \\
\hline $\begin{array}{c}\text { Spot number } \\
\text { Cytokine } \\
\text { activity }\end{array}$ & $88.6 \%$ & $88.6 \%$ & $71.4 \%$ & $90.0 \%$ & $90.0 \%$ & $100 \%$ \\
\hline
\end{tabular}

Figure 4. Comparison of ELISPOT assay responses between spot numbers and cytokine activity from patient cytotoxic T lymphocytes (CTLs) stimulated with various antigen peptides. (A) ELISPOT assay responses stimulated with CMVpp65, MAGEA3, and WT-1 peptides. (B) Comparison of sensitivity and specificity rate between spot numbers and cytokine activity in peptide-stimulated ELISPOT assays. SE: Sensitivity rate; SP: specificity rate.

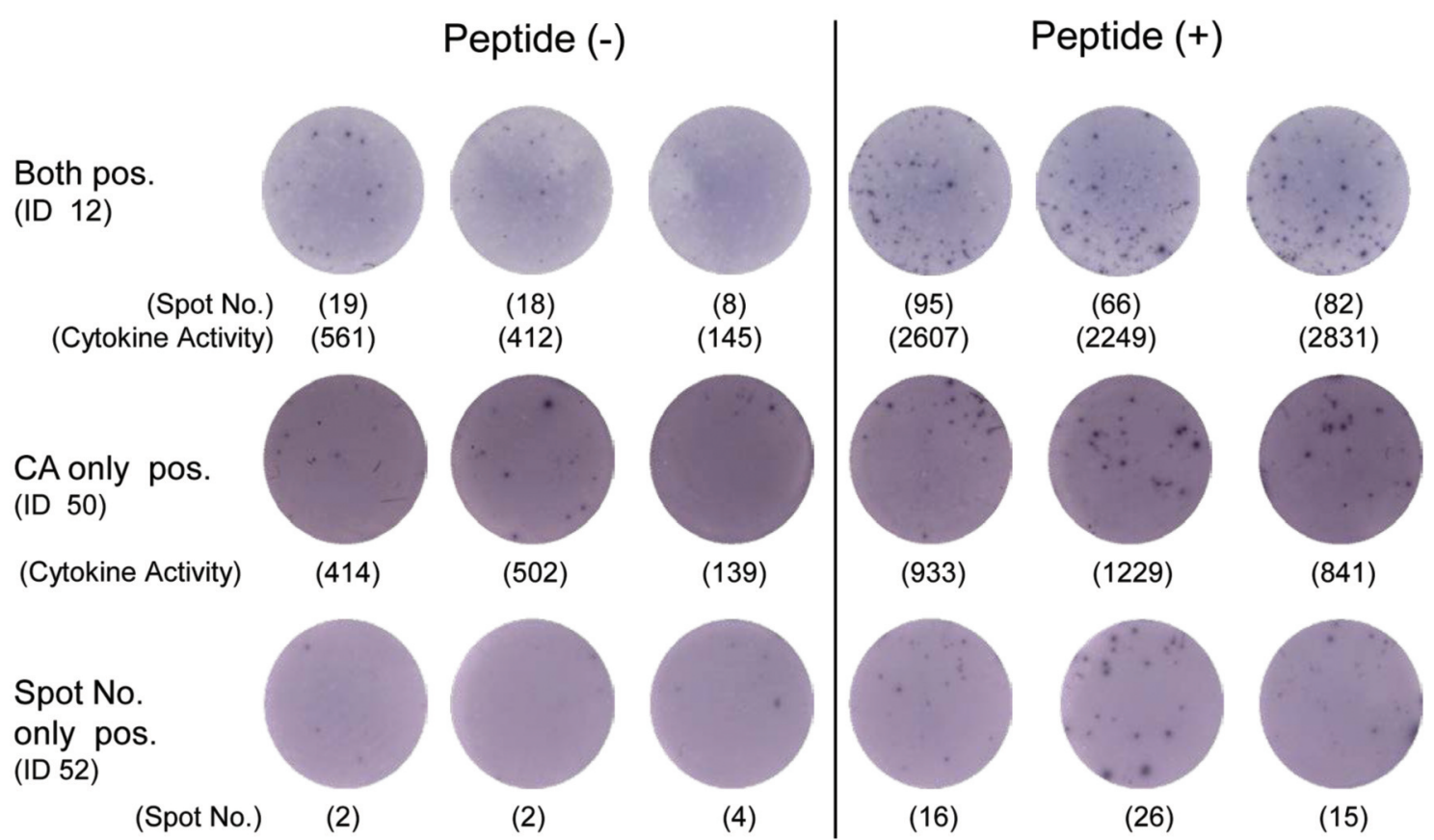

Figure 5. Representative images of ELISPOT wells from spot number- and cytokine activity-positive cases. Both pos.: both spot number and cytokine activity positive from assay ID 12; CA only pos.: cytokine activity positive only from assay ID 50; Spot No. only pos.: spot number positive only from assay ID 52. The values in the parentheses show actual spot number or cytokine activity parameter data. Peptide (-): cytotoxic T lymphocyte (CTL) cultures without a CMV peptide, Peptide (+): CTL cultures stimulated with a CMV peptide. 
IL-2, TNF- $\alpha$, and granzyme B-specific T cell assay using a fluoro-X software system (26). The second is notable advances in single-cell assays beyond the ELISPOT assay, such as next generation sequencing-based RNA-seq on a single-cell basis. The high sensitivity of the ELISPOT assay has been emphasized thus far; however, novel detection systems using microfluidics or microchamber and RNA-seqbased NGS technologies have been demonstrated to contribute to precise single-cell analysis beyond the capability of the ELISPOT assay (27-29).

In the current study, we focused on a novel ELISPOT parameter, cytokine activity, and compared data for this parameter with commonly available spot number data. Eventually, cytokine activity did not show any advantages in the efficiency to evaluate $\mathrm{T}$ cell immune responses than the existing spot number parameter, although cytokine activity is a novel parameter unreported so far. However, the cytokine activity parameter might be helpful in recognizing relatively few and large spots with high intensity and the spot number parameter does not usually contribute to the decision for a positive response. A substantial evaluation of cytokine activity compared with spot number in the future could be an alternative parameter referrable to spot evaluation in the ELISPOT assay.

\section{Conflicts of Interest}

The Authors declare that they have no competing interests in relation to this study.

\section{Authors' Contributions}

$\mathrm{CM}$ and Yasuto Akiyama participated in the design of the study and drafting of the manuscript and were responsible for completing the study. AI, HM, and Yoshiaki Abe carried out apheresis and were responsible for the immune cell analysis. RK, TA, AK, and KW participated in the design of the experiments and performed the biological assays. SD, KM and $\mathrm{NH}$ were responsible for the clinical work of the study and collection of PBMCs and other clinical samples. KY reviewed the manuscript. All Authors read and approved the final draft.

\section{Acknowledgements}

The Authors thank the medical doctors and other staff at the Shizuoka Cancer Center Hospital for collecting blood samples from cancer patients. This work was supported by a grant to Yasuto Akiyama from JSPS KAKENHI (Grant Number 20K07649), Japan.

\section{References}

1 Czerkinsky CC, Nilsson LA, Nygren H, Ouchterlony $\mathrm{O}$ and Tarkowski A: A solid-phase enzyme-linked immunospot (ELISPOT) assay for enumeration of specific antibody-secreting cells. J Immunol Methods 65(1-2): 109-121, 1983. PMID: 6361139. DOI: 10.1016/0022-1759(83)90308-3
2 Czerkinsky C, Andersson G, Ekre HP, Nilsson LA, Klareskog L and Ouchterlony O: Reverse ELISPOT assay for clonal analysis of cytokine production. I. Enumeration of gamma-interferonsecreting cells. J Immunol Methods 110(1): 29-36, 1988. PMID: 3131436. DOI: 10.1016/0022-1759(88)90079-8

3 Currier JR, Kuta EG, Turk E, Earhart LB, Loomis-Price L, Janetzki S, Ferrari G, Birx DL and Cox JH: A panel of MHC class I restricted viral peptides for use as a quality control for vaccine trial ELISPOT assays. J Immunol Methods 260(1-2): 157-172, 2002. PMID: 11792386. DOI: 10.1016/s0022-1759(01)00535-x

4 Zuber B, Levitsky V, Jönsson G, Paulie S, Samarina A, Grundström S, Metkar S, Norell H, Callender GG, Froelich C and Ahlborg N: Detection of human perforin by ELISpot and ELISA: ex vivo identification of virus-specific cells. J Immunol Methods 302(1-2): 13-25, 2005. PMID: 16005014. DOI: 10.1016/j.jim.2005.04.015

5 Meier T, Eulenbruch HP, Wrighton-Smith P, Enders G and Regnath T: Sensitivity of a new commercial enzyme-linked immunospot assay (T SPOT-TB) for diagnosis of tuberculosis in clinical practice. Eur J Clin Microbiol Infect Dis 24(8): 529-536, 2005. PMID: 16133410. DOI: 10.1007/s10096-005-1377-8

6 Streeck H, Frahm N and Walker BD: The role of IFN-gamma Elispot assay in HIV vaccine research. Nat Protoc 4(4): 461-469, 2009. PMID: 19282851. DOI: 10.1038/nprot.2009.7

7 Kenter GG, Welters MJ, Valentijn AR, Lowik MJ, Berends-van der Meer DM, Vloon AP, Essahsah F, Fathers LM, Offringa R, Drijfhout JW, Wafelman AR, Oostendorp J, Fleuren GJ, van der Burg SH and Melief CJ: Vaccination against HPV-16 oncoproteins for vulvar intraepithelial neoplasia. N Engl J Med 361(19): 18381847, 2009. PMID: 19890126. DOI: 10.1056/NEJMoa0810097

8 Sheikh NA, Petrylak D, Kantoff PW, Dela Rosa C, Stewart FP, Kuan LY, Whitmore JB, Trager JB, Poehlein CH, Frohlich MW and Urdal DL: Sipuleucel-T immune parameters correlate with survival: an analysis of the randomized phase 3 clinical trials in men with castration-resistant prostate cancer. Cancer Immunol Immunother 62(1): 137-147, 2013. PMID: 22865266. DOI: $10.1007 / \mathrm{s} 00262-012-1317-2$

9 Sundararaman S, Karulin AY, Ansari T, BenHamouda N, Gottwein J, Laxmanan S, Levine SM, Loffredo JT, McArdle S, Neudoerfl C, Roen D, Silina K, Welch M and Lehmann PV: High reproducibility of ELISPOT counts from nine different laboratories. Cells 4(1): 2139, 2015. PMID: 25585297. DOI: 10.3390/cells4010021

10 Janetzki S, Britten CM, Kalos M, Levitsky HI, Maecker HT, Melief CJ, Old LJ, Romero P, Hoos A and Davis MM: "MIATA"minimal information about T cell assays. Immunity 31(4): 527-528, 2009. PMID: 19833080. DOI: 10.1016/j.immuni.2009.09.007

11 Janetzki S, Panageas KS, Ben-Porat L, Boyer J, Britten CM, Clay TM, Kalos M, Maecker HT, Romero P, Yuan J, Kast WM, Hoos A and Elispot Proficiency Panel of the CVC Immune Assay Working Group: Results and harmonization guidelines from two large-scale international Elispot proficiency panels conducted by the Cancer Vaccine Consortium (CVC/SVI). Cancer Immunol Immunother 57(3): 303-315, 2008. PMID: 17721781. DOI: 10.1007/s00262-007-0380-6

12 Janetzki S and Britten CM: The impact of harmonization on ELISPOT assay performance. Methods Mol Biol 792: 25-36, 2012. PMID: 21956498. DOI: 10.1007/978-1-61779-325-7_2

13 Slota M, Lim JB, Dang Y and Disis ML: ELISpot for measuring human immune responses to vaccines. Expert Rev Vaccines 10(3): 299-306, 2011. PMID: 21434798. DOI: 10.1586/erv.10.169 
14 Ranieri E, Popescu I and Gigante M: CTL ELISPOT assay Methods Mol Biol 1186: 75-86, 2014. PMID: 25149304. DOI: 10.1007/978-1-4939-1158-5_6

15 Dittrich M and Lehmann PV: Statistical analysis of ELISPOT assays. Methods Mol Biol 792: 173-183, 2012. PMID: 21956510. DOI: 10.1007/978-1-61779-325-7_14

16 Karulin AY and Lehmann PV: How ELISPOT morphology reflects on the productivity and kinetics of cells' secretory activity. Methods Mol Biol 792: 125-143, 2012. PMID: 21956507. DOI: 10.1007/978-1-61779-325-7_11

17 Sibley LS, White AD, Marriott A, Dennis MJ, Williams A, Marsh PD and Sharpe SA: ELISPOT refinement using spot morphology for assessing host responses to tuberculosis. Cells 1(1): 5-14, 2012. PMID: 24710359. DOI: 10.3390/cells1010005

18 Oshita C, Takikawa M, Kume A, Miyata H, Ashizawa T, Iizuka A, Kiyohara Y, Yoshikawa S, Tanosaki R, Yamazaki N, Yamamoto A, Takesako K, Yamaguchi K and Akiyama Y: Dendritic cell-based vaccination in metastatic melanoma patients: phase II clinical trial. Oncol Rep 28(4): 1131-1138, 2012. PMID: 22895835. DOI: 10.3892/or.2012.1956

19 Akiyama Y, Oshita C, Kume A, Iizuka A, Miyata H, Komiyama M, Ashizawa T, Yagoto M, Abe Y, Mitsuya K, Watanabe R, Sugino T, Yamaguchi K and Nakasu Y: $\alpha$-type-1 polarized dendritic cell-based vaccination in recurrent high-grade glioma: a phase I clinical trial. BMC Cancer 12: 623, 2012. PMID: 23270484. DOI: 10.1186/1471-2407-12-623

20 Akiyama Y, Komiyama M, Nakamura Y, Iizuka A, Oshita C, Kume A, Nogami M, Miyata H, Ashizawa T, Yoshikawa S, Kiyohara Y and Yamaguchi K: Identification of novel MAGEA6- and MAGE-A12-derived HLA-A24-restricted cytotoxic T lymphocyte epitopes using an in silico peptide-docking assay. Cancer Immunol Immunother 61(12): 2311-2319, 2012. PMID: 22707303. DOI: $10.1007 / \mathrm{s} 00262-012-1298-1$

21 Kanda Y: Investigation of the freely available easy-to-use software 'EZR' for medical statistics. Bone Marrow Transplant 48(3): 452458, 2013. PMID: 23208313. DOI: 10.1038/bmt.2012.244

22 Janetzki S, Price L, Schroeder H, Britten CM, Welters MJ and Hoos A: Guidelines for the automated evaluation of Elispot assays. Nat Protoc 10(7): 1098-1115, 2015. PMID: 26110715. DOI: $10.1038 /$ nprot.2015.068
23 Janetzki S: Mastering the computational challenges of Elispot plate evaluation. Methods Mol Biol 1808: 9-30, 2018. PMID: 29956170. DOI: $10.1007 / 978-1-4939-8567-8 \_2$

24 Moodie Z, Price L, Gouttefangeas C, Mander A, Janetzki S, Löwer M, Welters MJ, Ottensmeier C, van der Burg SH and Britten CM: Response definition criteria for ELISPOT assays revisited. Cancer Immunol Immunother 59(10): 1489-1501, 2010. PMID: 20549207. DOI: 10.1007/s00262-010-0875-4

25 Jahnmatz P, Bengtsson T, Zuber B, Färnert A and Ahlborg N: An antigen-specific, four-color, B-cell FluoroSpot assay utilizing tagged antigens for detection. J Immunol Methods 433: 23-30, 2016. PMID: 26930550. DOI: 10.1016/j.jim.2016.02.020

26 Megyesi Z, Lehmann PV and Karulin AY: Multi-color FLUOROSPOT counting using ImmunoSpot ${ }^{\circledR}$ Fluoro- $X^{\text {TM }}$ suite. Methods Mol Biol 1808: 115-131, 2018. PMID: 29956178. DOI: 10.1007/978-1-4939-8567-8_10

27 Liu L, Chen D, Wang J and Chen J: Advances of single-cell protein analysis. Cells 9(5): 1271, 2020. PMID: 32443882. DOI: 10.3390/cells9051271

28 Chen Z, Chen JJ and Fan R: Single-cell protein secretion detection and profiling. Annu Rev Anal Chem (Palo Alto Calif) 12(1): 431-449, 2019. PMID: 30978293. DOI: 10.1146/annurevanchem-061318-115055

29 Savas P, Virassamy B, Ye C, Salim A, Mintoff CP, Caramia F, Salgado R, Byrne DJ, Teo ZL, Dushyanthen S, Byrne A, Wein L, Luen SJ, Poliness C, Nightingale SS, Skandarajah AS, Gyorki DE, Thornton CM, Beavis PA, Fox SB, Kathleen Cuningham Foundation Consortium for Research into Familial Breast Cancer (kConFab), Darcy PK, Speed TP, Mackay LK, Neeson PJ and Loi S: Single-cell profiling of breast cancer T cells reveals a tissue-resident memory subset associated with improved prognosis. Nat Med 24(7): 986-993, 2018. PMID: 29942092. DOI: $10.1038 / \mathrm{s} 41591-018-0078-7$
Received June 2, 2021

Revised June 27, 2021

Accepted June 28, 2021 